\title{
Performance of Omnipod Personalized Model Predictive Control Algorithm with Moderate Intensity Exercise in Adults with Type 1 Diabetes
}

\author{
Gregory P. Forlenza, MD, Bruce A. Buckingham, MD, ${ }^{2}$ Mark P. Christiansen, MD, ${ }^{3}$ \\ R. Paul Wadwa, MD, Thomas A. Peyser, $\mathrm{PhD}^{4}$ Joon Bok Lee, $\mathrm{PhD}^{5}$ Jason $\mathrm{O}^{\prime}$ Connor, $\mathrm{BS}^{5}$ \\ Eyal Dassau, PhD, ${ }^{6}$ Lauren M. Huyett, $\mathrm{PhD}^{5}$ Jennifer E. Layne, $\mathrm{PhD}^{5}$ \\ and Trang T. Ly, MBBS, FRACP, PhD 5
}

\begin{abstract}
Background: The objective of this study was to assess the safety and performance of the Omnipod ${ }^{\circledR}$ personalized model predictive control (MPC) algorithm with variable glucose setpoints and moderate intensity exercise using an investigational device in adults with type 1 diabetes (T1D).

Materials and Methods: A supervised 54-h hybrid closed-loop (HCL) study was conducted in a hotel setting after a 7-day outpatient standard treatment phase. Adults aged 18-65 years with T1D and HbA1c between $6.0 \%$ and $10.0 \%$ were eligible. Subjects completed two moderate intensity exercise sessions of $>30$ min duration on consecutive days: the first with the glucose set point increased from 130 to $150 \mathrm{mg} / \mathrm{dL}$ and the second with a temporary basal rate of $50 \%$, both started $90 \mathrm{~min}$ pre-exercise. Primary endpoints were percentage time in hypoglycemia $<70 \mathrm{mg} / \mathrm{dL}$ and hyperglycemia $\geq 250 \mathrm{mg} / \mathrm{dL}$.

Results: Twelve subjects participated in the study, with (mean \pm standard deviation) age $36.5 \pm 14.4$ years, diabetes duration $21.7 \pm 15.7$ years, $\mathrm{HbA} 1 \mathrm{c} 7.6 \% \pm 1.1 \%$, and total daily dose $0.60 \pm 0.22 \mathrm{U} / \mathrm{kg}$. Outcomes for the $54-\mathrm{h}$ HCL period were mean glucose: $136 \pm 14 \mathrm{mg} / \mathrm{dL}$, percentage time $<70 \mathrm{mg} / \mathrm{dL}: 1.4 \% \pm 1.3 \%, 70$ $180 \mathrm{mg} / \mathrm{dL}: 85.1 \% \pm 9.3 \%$, and $\geq 250 \mathrm{mg} / \mathrm{dL}: 1.8 \% \pm 2.4 \%$. In the $12-\mathrm{h}$ period after exercise start, percentage time $<70 \mathrm{mg} / \mathrm{dL}$ was $1.4 \% \pm 2.7 \%$ with the raised glucose set point and $1.6 \% \pm 3.0 \%$ with reduced basal rate. The percentage time $<70 \mathrm{mg} / \mathrm{dL}$ overnight was $0 \% \pm 0 \%$ on both study nights.

Conclusions: The Omnipod personalized MPC algorithm performed well and was safe during day and night use in response to variable glucose set points and with temporarily raised glucose set point or reduced basal rate $90 \mathrm{~min}$ in advance of moderate intensity exercise in adults with T1D.
\end{abstract}

Keywords: Artificial pancreas, Automated insulin delivery, Exercise, Closed-loop, Omnipod, Tubeless insulin pump.

\footnotetext{
${ }^{1}$ Barbara Davis Center for Diabetes, University of Colorado School of Medicine, Aurora, Colorado.

${ }^{2}$ Division of Pediatric Endocrinology, Department of Pediatrics, Stanford University, Stanford, California.

${ }^{3}$ Diablo Clinical Research, Walnut Creek, California.

${ }^{4}$ ModeAGC LLC, Palo Alto, California.

${ }^{5}$ Insulet Corporation, Acton, Massachusetts.

${ }^{6}$ Harvard John A. Paulson School of Engineering and Applied Sciences, Harvard University, Cambridge, Massachusetts.

Data included in this article were presented, in part, at the 11th International Conference on Advanced Technologies \& Treatments for Diabetes in Vienna, Austria, in 2018 and the Diabetes Technology Meeting in Bethesda, Maryland, in 2017.

(c) Gregory P. Forlenza, et al., 2019; Published by Mary Ann Liebert, Inc. This Open Access article is distributed under the terms of the Creative Commons License (http://creativecommons.org/licenses/by/4.0), which permits unrestricted use, distribution, and reproduction in any medium, provided the original work is properly credited.
} 


\section{Introduction}

$\mathbf{M}$ AINTAINING SAFE GLYCEMIC control during and after exercise is a challenge in managing type 1 diabetes (T1D). Exercise can provide many health benefits; however, fear of hypoglycemia and the loss of glycemic control may make participation in exercise difficult or daunting for people with T1D. ${ }^{1-4}$ Although there are extensive guidelines on the management of T1D during exercise, including recommended adjustments to insulin dosage and carbohydrate (CHO) consumption before, during, and after exercise, ${ }^{1}$ these guidelines can be challenging to implement in everyday life, and may not be adequate to prevent hypoglycemia during or after exercise.

Automated insulin delivery in response to continuous glucose monitor (CGM) signal has the potential to lower the barrier to exercise for people with T1D by improving glycemic outcomes and reducing the burden of management. Several studies have examined the performance of a single-hormone artificial pancreas (AP) system in response to exercise. The majority of these studies included exercise as part of the protocol without any announcement or adjustment to the algorithm. $^{5-14}$ A few studies have included a user-initiated announcement of exercise ${ }^{15-18}$ or pre-exercise snacks, ${ }^{19}$ whereas others have included automatic detection of exercise through accelerometers or heart rate monitors. ${ }^{20-23}$ These studies have varied widely in the type of AP system, duration of use, duration and intensity of exercise, announcement strategy, amount and frequency of snacks, and outcomes reported, making it difficult to compare results directly or draw conclusions about which approach was most successful. However, in general, these studies have demonstrated that AP systems are able to maintain good glycemic control while reducing the occurrence of hypoglycemia, but supplemental $\mathrm{CHO}$ consumption is sometimes still necessary before, during, or after exercise to prevent or treat hypoglycemia.

The Omnipod Horizon ${ }^{\mathrm{TM}}$ Automated Glucose Control System is a single-hormone hybrid closed-loop (HCL) system using a personalized model predictive control (MPC) algorithm under development for commercial application. $^{24,25}$ The objective of this study was to evaluate the safety and performance of the Omnipod personalized MPC algorithm in adults with T1D performing moderate intensity exercise in a supervised outpatient hotel setting. Although exercise safety was assessed using both glucose set point increase and basal rate reduction, the intent of this study was not to determine which method was superior but rather to test that both methods were safe and performed well.

\section{Materials and Methods}

\section{Study design}

This single-arm multicenter study assessed the Omnipod personalized MPC algorithm performance for $54 \mathrm{~h}$ with variable glucose set points in a supervised hotel setting, with the HCL period commencing before breakfast on day 1 and ending $\sim 5 \mathrm{~h}$ after breakfast on day 3 (Fig. 1). Participants engaged in a session of moderate intensity exercise lasting $>30 \mathrm{~min}$ on each subsequent study afternoon at $\sim 1600 \mathrm{~h}$,
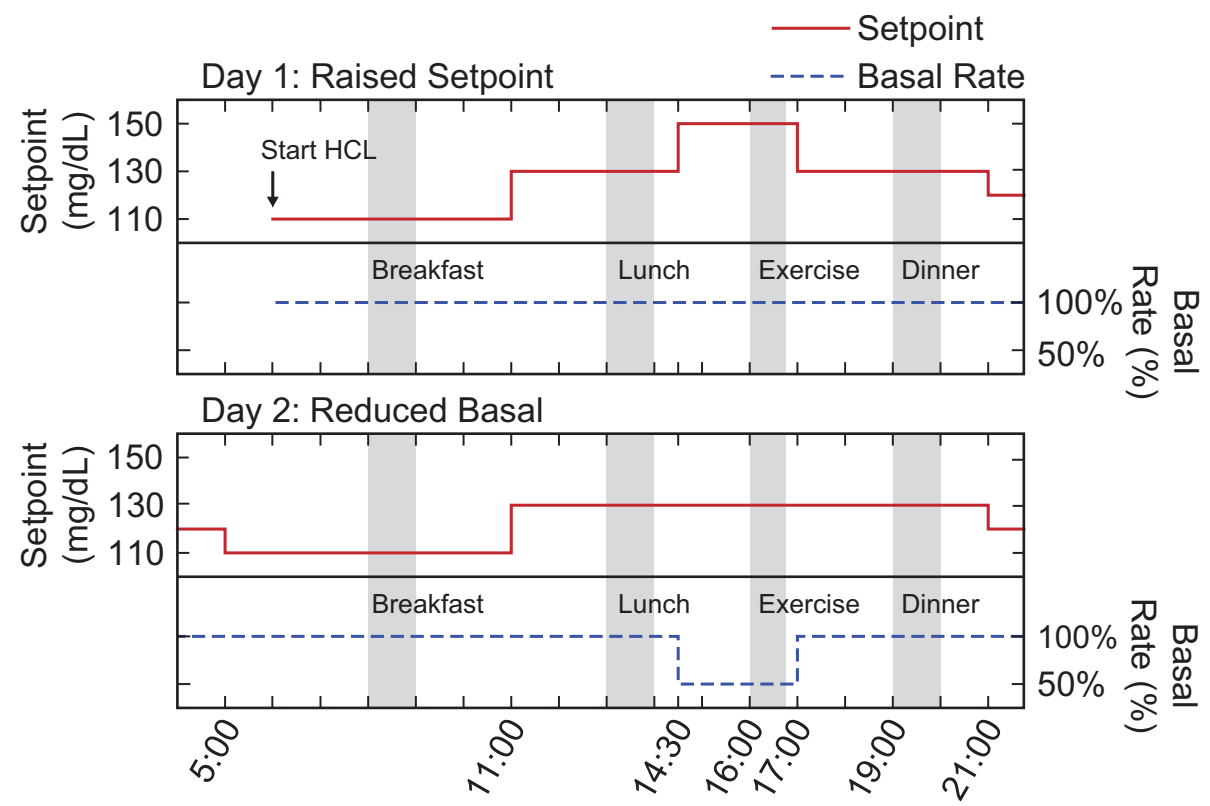

Time of Day (h)

FIG. 1. Representation of the algorithm input settings of glucose set point (mg/dL) and basal rate (\% of usual rate) on each study day with exercise. On study day 1 , the glucose set point was raised to $150 \mathrm{mg} / \mathrm{dL} 90$ min before exercise start (approximate timing indicated by gray bar labeled Exercise), whereas the basal rate was maintained at $100 \%$ of the usual rate (top panel). On study day 2, the basal rate was decreased to $50 \%$ of the usual rate 90 min before exercise, whereas the glucose set point was maintained at $130 \mathrm{mg} / \mathrm{dL}$ (bottom panel). On both days, the glucose set point was set to $110 \mathrm{mg} / \mathrm{dL}$ in the early morning $(05: 00 \mathrm{~h})$, increased to $130 \mathrm{mg} / \mathrm{dL}$ in the late morning $(11: 00 \mathrm{~h})$, and lowered to $120 \mathrm{mg} / \mathrm{dL}$ in the late evening $(21: 00 \mathrm{~h})$. The approximate meal times are indicated by gray bars labeled with meal type. On Study day 3 , the glucose set point was set to $110 \mathrm{mg} / \mathrm{dL}$ in the early morning $(05: 00 \mathrm{~h})$, and HCL ended $\sim 5 \mathrm{~h}$ after breakfast (not shown). HCL, hybrid closed loop. 
with example activities including soccer, basketball, and treadmill use. Exercise activities were similar on each day.

The algorithm was evaluated under two experimental conditions before exercise in a nonrandomized order: a temporary increase in the glucose set point or reduction of the preprogrammed subject-specific basal rate (Fig. 1). Ninety minutes before the first exercise session, the glucose set point was raised from 130 to $150 \mathrm{mg} / \mathrm{dL}$, with the basal rate unchanged at $100 \%$ of the baseline rate. Ninety minutes before the second exercise session, a temporary basal rate reduction of 50\% was implemented, with the glucose set point unchanged at $130 \mathrm{mg} / \mathrm{dL}$. In both cases, the glucose set point and basal rate settings were returned to their original values at the end of exercise and dinner was consumed $\sim 2 \mathrm{~h}$ later. As a safety requirement, capillary blood glucose (BG) was required to be $\geq 120 \mathrm{mg} / \mathrm{dL}$ before commencing exercise. If capillary BG was $<120 \mathrm{mg} / \mathrm{dL}$, supplemental $\mathrm{CHO}$ was consumed without bolus until capillary BG was $\geq 120 \mathrm{mg} / \mathrm{dL}$.

Throughout each study day, the glucose set point was changed according to the following schedule (in addition to the previously described changes made before exercise): start at $110 \mathrm{mg} / \mathrm{dL}$ in the early morning $(05: 00 \mathrm{~h})$, increase to $130 \mathrm{mg} / \mathrm{dL}$ in the late morning $(11: 00 \mathrm{~h})$, and lower to $120 \mathrm{mg} / \mathrm{dL}$ in the late evening $(21: 00 \mathrm{~h})$ (Fig. 1). Subjects selected all meals from a variety of options containing 30$90 \mathrm{~g} \mathrm{CHO}$ on the first day, with identical meals repeated on the second day for consistency between the 2 days with exercise sessions. Meal boluses were calculated by the system based on the amount of $\mathrm{CHO}$ estimated by the subject. This amount could be adjusted based on investigator judgment as needed. A correction or reverse bolus based on a recent capillary BG measurement could be given with the meal bolus at the discretion of the investigator or subject.

The HCL study was preceded by a 7-day outpatient standard treatment phase, during which subjects managed their diabetes at home per their usual routine using their personal insulin pump and a Dexcom G4 505 Share ${ }^{\circledR}$ CGM (Dexcom, San Diego, CA). Pump settings were adjusted as needed by the investigator, based upon their clinical judgment.

\section{Study participants}

The following were inclusion criteria for the study: age $18-65$ years, T1D for $\geq 1$ year, $\mathrm{HbA} 1 \mathrm{c}>6 \%$ and $\leq 10 \%$ at screening, use of any insulin pump for $\geq 6$ months, and total daily dose of insulin $\geq 0.3 \mathrm{U} / \mathrm{kg}$. Subjects with $\geq 1$ episode of severe hypoglycemia or diabetic ketoacidosis requiring an emergency room visit or hospitalization within the past 6 months, with hypoglycemic unawareness assessed by the Clarke Questionnaire, ${ }^{26}$ or who were pregnant or lactating were excluded. Each study site received Institutional Review Board approval and subjects provided written informed consent (Clinicaltrials.gov registration NCT03064906).

\section{Safety and monitoring}

Study staff monitored subjects' status throughout the HCL study period, with hypoglycemia (capillary BG $<70 \mathrm{mg} / \mathrm{dL}$ or symptomatic) or severe hyperglycemia (capillary BG $\geq 300 \mathrm{mg} / \mathrm{dL}$ ) treated per standard practice. ${ }^{27} \mathrm{HCL}$ stopping criteria included $\mathrm{BG} \geq 300 \mathrm{mg} / \mathrm{dL}$ and ketones $\geq 3.0 \mathrm{mmol} / \mathrm{L}$, subjects unable to take oral $\mathrm{CHO}$, loss of consciousness, seizure, or subject request.

\section{Investigational device}

The investigational HCL system used in this study has been described previously. ${ }^{24,25}$ The system uses a modified version of the Omnipod ${ }^{\circledR}$ Insulin Management System (Insulet Corp., Acton, MA) tubeless insulin pump (Pod) for insulin delivery, a modified personal diabetes manager (PDM), the Dexcom G4 505 Share AP System, and the Omnipod personalized MPC algorithm running on a Windows 10 tablet configured with the portable AP System. ${ }^{28}$ Operationally, the Dexcom CGM receiver communicated with the portable AP system (tablet) through a wired USB connection. The portable AP system transmitted insulindosing commands to the PDM through Bluetooth low energy relay. The PDM subsequently controlled insulin delivery by the Pod through a radiofrequency signal. The tablet was used to start each Pod, initiate HCL, display CGM and insulin delivery data, and for meal bolus delivery. ${ }^{24,25}$

Inputs to the investigational Omnipod personalized MPC algorithm included the subject-specific basal rate profile, total daily insulin dose, and the glucose set point. Correction factor and insulin-to-carbohydrate ratio are also entered into the system to be used for calculation of meal boluses and correction boluses. The Omnipod personalized MPC algorithm insulin-dosing decisions are made every 5 min based on CGM values to minimize the deviation between predicted BG for a 60-min horizon and the target glucose set point, while also minimizing deviations from the preprogrammed subject-specific basal rate. ${ }^{24,25}$ Temporary changes could be made to the subject-specific basal rate profile and glucose set point using the system interface. These parameters were adjusted during the study as described in Study Design (Fig. 1).

\section{Outcomes}

The primary endpoints of this study were safety parameters of percentage of time the sensor glucose was in a hypoglycemic range, defined as $<70 \mathrm{mg} / \mathrm{dL}$, and hyperglycemic range, defined as $\geq 250 \mathrm{mg} / \mathrm{dL}$, during the 54-h HCL study period with variable glucose set points. Secondary endpoints for the 54-h HCL study period included mean sensor glucose, percentage time with sensor glucose $<54,<60,70-140,70$ $180,>180$, and $\geq 300 \mathrm{mg} / \mathrm{dL}$, and standard deviation (SD) and coefficient of variation $(\mathrm{CV})$ of sensor glucose values. ${ }^{29}$ Additional endpoints were the immediate $(2 \mathrm{~h})$ and delayed (up to $24 \mathrm{~h}$ ) sensor glucose response to moderate intensity exercise with a temporary raised glucose set point or reduced basal rate $90 \mathrm{~min}$ before exercise.

\section{Statistical analysis}

As the primary endpoint for the study was safety, sample size was not determined by power calculation. Prespecified descriptive statistical analyses were performed for all subjects who entered the study $(n=12)$. Results were summarized for the 54-h HCL study period (overall) and the overnight period defined as 23:00 h to 07:00 h. Results were also summarized for the exercise sessions. Outcomes were calculated per subject and summarized as mean \pm SD or median (interquartile range), unless otherwise indicated. Statistical analyses were performed using $\operatorname{SAS}^{\circledR} 9.3$ or later (SAS Institute, Cary, NC). 
Table 1. Characteristics of the Study Population

\begin{tabular}{lc}
\hline Characteristic & Subjects $(\mathrm{n}=12)$ \\
\hline Age, years (range) & $36.5 \pm 14.4(22.5-64.6)$ \\
Female, \% & 50 \\
Diabetes duration, years (range) & $21.7 \pm 15.7(4.2-51.7)$ \\
Insulin pump use duration, & $11.4 \pm 6.8(3.3-28.2)$ \\
$\quad$ years (range) & \\
Insulin dose pre-HCL, $\mathrm{U} /(\mathrm{kg} \cdot \mathrm{d})^{\mathrm{a}}$ & $0.60 \pm 0.22$ \\
Insulin dose 24-h HCL, $\mathrm{U} /(\mathrm{kg} \cdot \mathrm{d})^{\mathrm{b}}$ & $0.48 \pm 0.11$ \\
$\mathrm{HbA1c} \%$ & $7.6 \pm 1.1^{\mathrm{c}}$ \\
\hline
\end{tabular}

Results are mean \pm SD unless otherwise indicated.

${ }^{a}$ Insulin dose averaged for the 7-day standard therapy run-in phase.

${ }^{\mathrm{b}}$ Insulin dose during entire HCL study period.

${ }^{\mathrm{c}}$ One subject with an $\mathrm{HbA} 1 \mathrm{c}$ of $5.6 \%$ was allowed to enroll based on investigator discretion.

HCL, hybrid closed loop; SD, standard deviation.

\section{Results}

The characteristics of the 12 subjects are reported in Table 1. A summary of the glycemic measures and pump setting adjustments for the 7-day standard treatment run-in phase is included in the Supplementary Data (Supplementary Fig. S1 and Supplementary Table S1).

\section{Glycemic outcomes}

The glycemic outcomes for the 54-h HCL study period with variable glucose set points overall, during daytime (07:00 23:00 h), and overnight (23:00-07:00 h) are given in Table 2. The percentage of time with sensor glucose in the hypoglycemic range of $<70 \mathrm{mg} / \mathrm{dL}$ was mean \pm SD: $1.4 \% \pm 1.3 \%$ during the $54-$ $\mathrm{h}$ HCL period overall and $0.0 \% \pm 0.0 \%$ overnight. The percentage of time with sensor glucose in the hyperglycemic range of $\geq 250 \mathrm{mg} / \mathrm{dL}$ was $1.8 \% \pm 2.4 \%$ for the overall $\mathrm{HCL}$ period and $0.1 \% \pm 0.3 \%$ overnight. The percentage of time with sensor glucose in the target range of 70 to $180 \mathrm{mg} / \mathrm{dL}$ was $85.1 \% \pm 9.3 \%$ overall and $93.4 \% \pm 14.2 \%$ overnight. The mean glucose was $136 \pm 14 \mathrm{mg} / \mathrm{dL}$ overall and $129 \pm 23 \mathrm{mg} / \mathrm{dL}$ overnight.

\section{Exercise challenge}

Exercise duration was $39 \pm 8 \mathrm{~min}$ and $38 \pm 6 \mathrm{~min}$ in the raised glucose set point and reduced basal rate conditions, respectively. The 24-h glycemic response to the moderate intensity exercise on each study day is shown in Figure 2. Glycemic outcomes for the 2 and $12 \mathrm{~h}$ periods from exercise start are given in Tables 3 and 4. Glycemic outcomes were similar with the raised glucose set point and reduced basal rate pre-exercise. Hypoglycemia treatments and supplemental CHO ingestion in the time periods before exercise through the subsequent overnight period are summarized in Table 5. There were no supplemental $\mathrm{CHO}$ or hypoglycemic episodes (capillary $\mathrm{BG}<70 \mathrm{mg} / \mathrm{dL}$ ) overnight in either group.

\section{Safety outcomes}

There were no serious adverse events, and the full HCL period was completed for all subjects with no instances of the stopping criteria being met. In the 648 patient-hours of HCL use, there were 0 hyperglycemic events involving capillary BG values $\geq 300 \mathrm{mg} / \mathrm{dL}$. There were 13 hypoglycemic events in 8 subjects involving capillary BG values $<70 \mathrm{mg} / \mathrm{dL}$, resulting in 15 oral $\mathrm{CHO}$ treatments given (8-21 g CHO). This is equivalent to 0.48 events per subject per day overall.

\section{Percentage time in $\mathrm{HCL}$}

The mean percentage of the total HCL study period spent with the system running in closed loop was $98.8 \% \pm 1.8 \%$ (range: $93.7 \%-100.0 \%$ ). There were no suspected infusion site failures during the HCL period. The causes for interruption of closed loop included Pod replacement, temporary loss of CGM communication, or loss of system battery charge.

\section{Discussion}

This multicenter feasibility study demonstrated that the Omnipod personalized MPC algorithm performed well and was safe during day and night use for $54 \mathrm{~h}$ in adults with T1D performing moderate intensity exercise with a temporary glucose set point increase or basal rate reduction $90 \mathrm{~min}$ before exercise. With each pre-exercise announcement strategy,

Table 2. Glycemic Outcomes During the 54-H Hybrid Closed-Loop Period

\begin{tabular}{lccc}
\hline Parameter & Overall $(54 \mathrm{~h})$ & Day $(07: 00-23: 00 \mathrm{~h})$ & Night $(23: 00-7: 00 \mathrm{~h})$ \\
\hline Mean sensor glucose, mg/dL & $136 \pm 14$ & $139 \pm 13$ & $129 \pm 23$ \\
Standard deviation, mg/dL & $38.5 \pm 8.6$ & $42.6 \pm 10.9$ & $19.6 \pm 6.3$ \\
Coefficient of variation, \% & $28.2 \pm 5.4$ & $30.4 \pm 6.8$ & $15.5 \pm 5.2$ \\
Percentage time in glucose range, $\%$ & & & \\
$<54 \mathrm{mg} / \mathrm{dL}$ & $0.2 \pm 0.3$ & $0.2 \pm 0.5$ & $0.0 \pm 0.0$ \\
& $0.0(0.0-0.1)$ & $0.0(0.0-0.1)$ & $0.0(0.0-0.0)$ \\
$<60 \mathrm{mg} / \mathrm{dL}$ & $0.5 \pm 0.6$ & $0.7 \pm 0.9$ & $0.0 \pm 0.0$ \\
& $0.1(0.0-0.8)$ & $0.1(0.0-1.2)$ & $0.0(0.0-0.0)$ \\
$<70 \mathrm{mg} / \mathrm{dL}$ & $1.4 \pm 1.3$ & $2.1 \pm 1.9$ & $0.0 \pm 0.0$ \\
$70-140 \mathrm{mg} / \mathrm{dL}$ & $1.7(0.0-2.4)$ & $2.4(0.0-3.5)$ & $0.0(0.0-0.0)$ \\
$70-180 \mathrm{mg} / \mathrm{dL}$ & $60.3 \pm 16.5$ & $56.1 \pm 13.2$ & $69.4 \pm 32.7$ \\
$>180 \mathrm{mg} / \mathrm{dL}$ & $85.1 \pm 9.3$ & $81.3 \pm 8.7$ & $93.4 \pm 14.2$ \\
$\geq 250 \mathrm{mg} / \mathrm{dL}$ & $13.5 \pm 9.5$ & $16.6 \pm 8.6$ & $6.6 \pm 14.2$ \\
$\geq 300 \mathrm{mg} / \mathrm{dL}$ & $1.8 \pm 2.4$ & $2.5 \pm 3.3$ & $0.1 \pm 0.3$ \\
\hline
\end{tabular}

Results are sensor glucose values, mean \pm SD or median (IQR); SI conversion factor to convert glucose to mmol/L, multiply by 0.0555 . $\mathrm{IQR}$, interquartile range. 


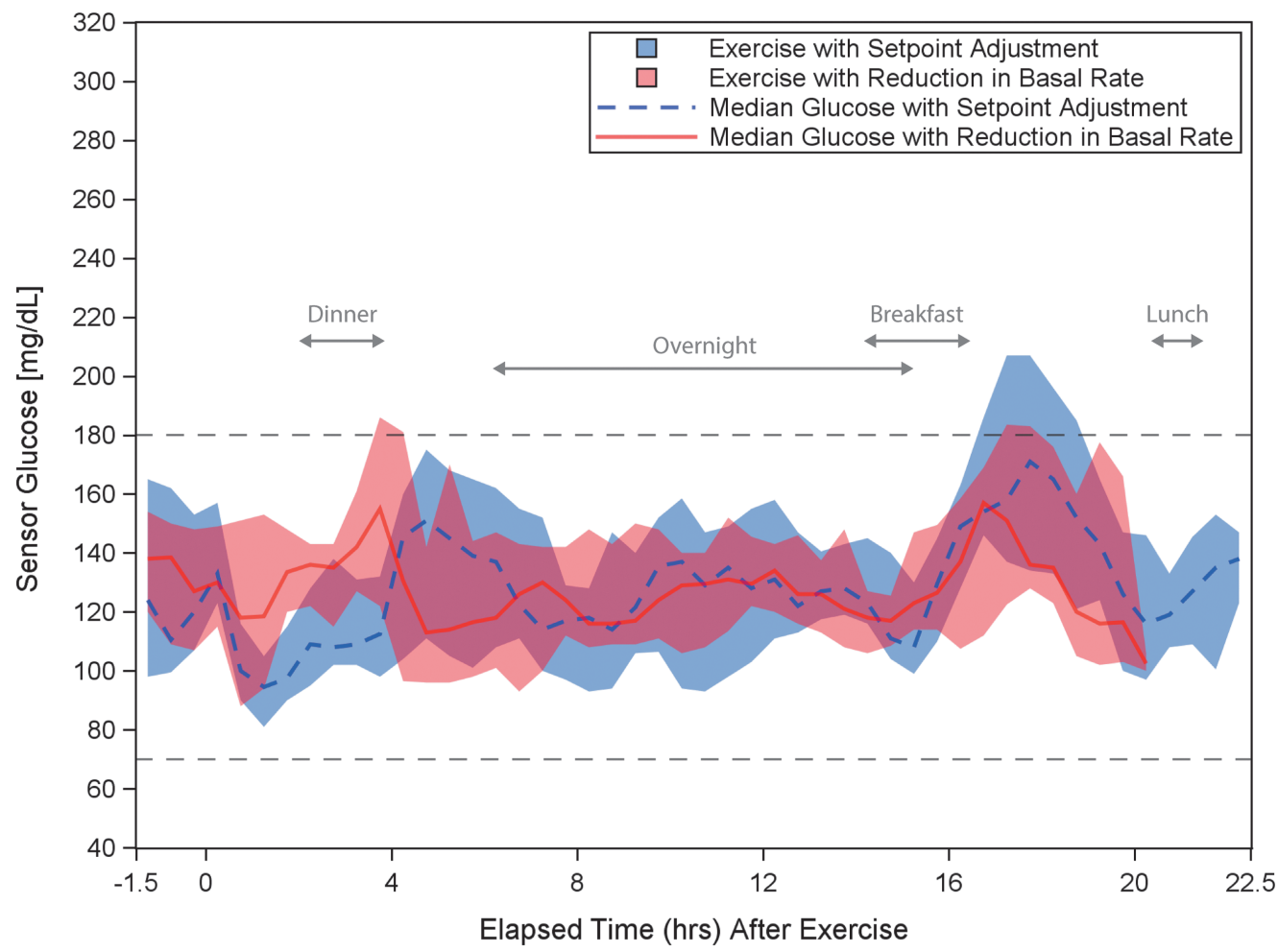

FIG. 2. Comparison of the glycemic response for the 12 participants for the $24 \mathrm{~h}$ period beginning 90 min before exercise start with glucose set point increase or reduction in basal rate. Median sensor glucose response is plotted for the 12 participants for $24 \mathrm{~h}$ after algorithm glucose set point increase (dashed blue line) or basal rate decrease (solid red line). The shaded area represents the IQR. Exercise start times ranged from 15:43 h to 16:48 h. The approximate ranges of time for dinner, the overnight period, breakfast, and lunch are labeled on the graph. The study ended $\sim 20 \mathrm{~h}$ after the start of exercise on day 2 and, therefore, the basal rate adjustment data series is limited to $20 \mathrm{~h}$ on the graph. The target range of $70-$ $180 \mathrm{mg} / \mathrm{dL}$ is indicated by black dashed lines. IQR, interquartile range.

the algorithm was able to attenuate insulin delivery to reduce the risk of immediate and delayed exercise-related hypoglycemia, with no instances of overnight hypoglycemia. Elimination of nocturnal hypoglycemia during this study period suggests that the combination of pre-exercise announcement with the Omnipod personalized MPC algorithm may be protective against overnight hypoglycemia after exercise. Importantly, there was no rebound hyperglycemia overnight after exercise. In addition, the system was safe when used with variable glucose set points throughout the day. To our knowledge, this was the first study to evaluate

Table 3. Glycemic Outcomes Pre-exercise AND FOR THE SHORT-TERM $(2 \mathrm{H})$ RESPONSE TO EXERCISE

\begin{tabular}{lcc}
\hline Mean glucose, $m g / d L$ & $\begin{array}{c}\text { Raised } \\
\text { set point }\end{array}$ & $\begin{array}{c}\text { Reduced } \\
\text { basal }\end{array}$ \\
\hline $\begin{array}{l}\text { Pre-exercise } \\
\quad 90 \text { min period before exercise start }\end{array}$ & $140 \pm 59$ & $136 \pm 26$ \\
$\begin{array}{l}\text { During exercise } \\
\quad \text { Period from exercise start to end }\end{array}$ & $140 \pm 32$ & $132 \pm 26$ \\
Postexercise & $100 \pm 19$ & $122 \pm 35$ \\
$\quad$ 60 min period after exercise end & $113 \pm 17$ & $128 \pm 26$ \\
$\begin{array}{l}\text { During and postexercise } \\
\text { 2 h period from exercise start }\end{array}$ & & \\
\hline
\end{tabular}

Results are sensor glucose values, mean \pm SD; SI conversion factor to convert glucose to $\mathrm{mmol} / \mathrm{L}$, multiply by 0.0555 . both the immediate and overnight responses to exercise during HCL when using an announcement strategy to reduce insulin delivery $90 \mathrm{~min}$ pre-exercise. Similar to approaches used to manage insulin delivery with exercise when using an insulin pump with standard therapy, these announcement strategies will require user engagement and may not be realistic for all situations; however, we have evaluated and found to be safe two simple approaches intended to reduce or prevent both immediate and delayed hypoglycemia after exercise during HCL.

Table 4. Glycemic Outcomes for the EXtended (12 H) Response to EXERCISE

\begin{tabular}{ccc}
\hline & Raised set point & Reduced basal \\
\hline Mean glucose, mg/dL & $127 \pm 24$ & $131 \pm 18$ \\
Percentage time in glucose range, $\%$ & \\
$<54 \mathrm{mg} / \mathrm{dL}$ & $0.7 \pm 1.5$ & $0 \pm 0$ \\
& $0.0(0.0-0.3)$ & $0.0(0.0-0.0)$ \\
$<70 \mathrm{mg} / \mathrm{dL}$ & $1.4 \pm 2.7$ & $1.6 \pm 3.0$ \\
& $0.0(0.0-1.7)$ & $0.0(0.0-2.1)$ \\
$70-180 \mathrm{mg} / \mathrm{dL}$ & $88.9 \pm 17.6$ & $89.1 \pm 11.3$ \\
$>180 \mathrm{mg} / \mathrm{dL}$ & $9.7 \pm 18.1$ & $9.2 \pm 11.8$ \\
$\geq 250 \mathrm{mg} / \mathrm{dL}$ & $0.9 \pm 3.2$ & $0.4 \pm 1.0$ \\
\hline
\end{tabular}

Results are sensor glucose values, mean $\pm \mathrm{SD}$, or median (IQR); $12 \mathrm{~h}$ period measured from the start of exercise; SI conversion factor to convert glucose to $\mathrm{mmol} / \mathrm{L}$, multiply by 0.0555 . 
Table 5. Supplemental Carbohydrates and Hypoglycemia Around Exercise

\begin{tabular}{|c|c|c|c|c|c|c|}
\hline \multirow[b]{2}{*}{ Time period } & \multicolumn{3}{|c|}{ Raised set point } & \multicolumn{3}{|c|}{ Reduced basal } \\
\hline & $\begin{array}{l}\text { Subjects with } \\
\text { supplemental } \\
C H O, \mathrm{n}^{\mathrm{a}}\end{array}$ & $\begin{array}{c}\text { Subjects with } \\
B G<70 \mathrm{mg} / \mathrm{dL}, \mathrm{n}\end{array}$ & $\begin{array}{l}\text { CHO per } \\
\text { subject } \\
\text { (range, g) }\end{array}$ & $\begin{array}{l}\text { Subjects with } \\
\text { supplemental } \\
\text { CHO, } \mathrm{n}^{\mathrm{a}}\end{array}$ & $\begin{array}{c}\text { Subjects } \\
\text { with } B G \\
<70 \mathrm{mg} / \mathrm{dL}, \mathrm{n}\end{array}$ & $\begin{array}{c}\text { CHO per } \\
\text { subject (range, } g \text { ) }\end{array}$ \\
\hline Before exercise $(90 \mathrm{~min})$ & 5 & 1 & $25-40$ & 5 & 0 & $16-27$ \\
\hline During exercise $(\sim 40 \mathrm{~min})$ & 1 & 0 & 12 & 0 & 0 & - \\
\hline Exercise end to dinner & 4 & 2 & $12-20$ & 3 & 1 & $14-17$ \\
\hline Dinner to overnight & 2 & 1 & $32-38$ & 1 & 0 & 17 \\
\hline Overnight (23:00-07:00 h) & 0 & 0 & - & 0 & 0 & - \\
\hline
\end{tabular}

${ }^{\text {a }}$ Supplemental CHOs are defined as $\mathrm{CHO}$ ingested without a corresponding insulin bolus. Includes participants consuming supplemental $\mathrm{CHOs}$ as treatment for capillary $\mathrm{BG}<70 \mathrm{mg} / \mathrm{dL}$, as well as for other reasons such as participant request or to qualify for exercise with capillary BG $>120 \mathrm{mg} / \mathrm{dL}$. For supplemental CHO consumption not associated with a capillary BG $<70 \mathrm{mg} / \mathrm{dL}$, subjects were counted if they consumed at least $12 \mathrm{~g}$ of $\mathrm{CHO}$ within a period of $15 \mathrm{~min}$ or less.

$\mathrm{BG}$, blood glucose; CHOs, carbohydrates.

The primary concern after exercise in patients with T1D is the risk of immediate or delayed hypoglycemia, especially overnight. ${ }^{1,30-34}$ Clinical evidence shows that reducing or suspending insulin at the start of exercise may not be adequate to prevent hypoglycemia, ${ }^{35,36}$ and that reducing insulin delivery $90 \mathrm{~min}$ before the start of exercise may be the best approach to attenuate hypoglycemia with exercise. ${ }^{36,37}$ In this study, we evaluated two options for an exercise announcement strategy to reduce insulin delivery $90 \mathrm{~min}$ before the start of exercise during HCL: raising the algorithm glucose set point or reducing the basal rate. The rationale behind each of these announcement strategies was to reduce the amount of insulin on board and bring the BG to a suitable level for the start of exercise, while allowing the algorithm to respond to the variation in insulin requirements that occurs post-exercise.

There was no hypoglycemia observed during the overnight periods after exercise. The absence of overnight hypoglycemia is promising compared with several recent studies of exercise using single-hormone HCL systems, whether the exercise was unannounced, announced at onset, or automatically detected, which have reported between $0.17 \%$ and $3 \%$ average time $<70 \mathrm{mg} / \mathrm{dL}$ overnight. ${ }^{9,13,17,23}$ A study of a dualhormone system with automatic exercise detection also showed $0.6 \%$ of time overnight $<70 \mathrm{mg} / \mathrm{dL}^{23}$

Although there was no hypoglycemia overnight, a small number of subjects experienced hypoglycemia in the shortterm period after exercise. Three subjects required treatment with supplemental $\mathrm{CHO}$ for capillary BG $<70 \mathrm{mg} / \mathrm{dL}$ after exercise with the glucose set point increase, and one subject with the basal rate reduction, all occurring within $3 \mathrm{~h}$ of exercise end. This result is consistent with previous studies, where use of a single- or dual-hormone HCL system with an announcement strategy in advance of exercise start was not able to prevent hypoglycemia during or shortly after exercise. $^{15,16}$ For example, Jayawardene et al. ${ }^{15}$ evaluated a single-hormone HCL system in adults with T1D performing 45 min of moderate intensity exercise, with the glucose set point raised from $120 \mathrm{mg} / \mathrm{dL}$ to 150 or $160 \mathrm{mg} / \mathrm{dL} 2 \mathrm{~h}$ preexercise. Despite the early glucose set point change, one subject experienced hypoglycemia immediately after exercise. In Taleb et al., ${ }^{16}$ adults with T1D completed $60 \mathrm{~min}$ of aerobic exercise while using a single- or dual-hormone HCL system, with the glucose set point raised from 95 to
$150 \mathrm{mg} / \mathrm{dL} 20 \mathrm{~min}$ before exercise start. Nine and three subjects experienced hypoglycemic events with $\mathrm{BG}<70 \mathrm{mg} / \mathrm{dL}$ after exercise with the single- and dual-hormone systems, respectively. The set point adjustment made $20 \mathrm{~min}$ preexercise may not have allowed a sufficient decrease in insulin on board, as compared with the recommended $90 \mathrm{~min}$ of reduced insulin delivery before exercise. ${ }^{1}$

A potential concern when reducing insulin delivery before exercise is the increased risk of delayed hyperglycemia; however, the exercise announcement strategies used in this study were not associated with increased hyperglycemia post-exercise. The percentages of time with CGM >180 and $\geq 250 \mathrm{mg} / \mathrm{dL}$ in the $12 \mathrm{~h}$ after exercise and overnight remained low and were consistent with overnight results previously reported for the Omnipod personalized MPC algorithm in adults not performing exercise ${ }^{25}$ (no data are available for direct comparison for $12 \mathrm{~h}$ post-exercise).

A review of the literature ${ }^{38}$ indicates that HCL systems may be expected to achieve at least $70 \%$ of sensor glucose values between 70 and $180 \mathrm{mg} / \mathrm{dL},<4 \%$ of values $<70 \mathrm{mg} / \mathrm{dL}$, a CV $<36 \%,{ }^{39}$ and a mean glucose of $\leq 155 \mathrm{mg} / \mathrm{dL}$, equivalent to an estimated HbAlc of 7.0\%. ${ }^{40,41}$ This study exceeded each of these overall glycemic control performance metrics, with $85.1 \%$ of sensor glucose values in the target range of 70 $180 \mathrm{mg} / \mathrm{dL}$ overall and an average CV of $28.2 \%$. In addition, the results compare favorably with other recent studies of HCL in adults with T1D participating in exercise, which have shown mean percentages of time in target range between $64 \%$ and $88 \% .^{9,13,17,22,23}$ The glycemic control metrics were exceeded in this study even in the presence of daily moderate intensity exercise sessions and with variable algorithm glucose set points throughout each day. These results provide the first demonstration of safe use of variable set points with the Omnipod personalized MPC algorithm.

The limitations of this study include the absence of a standard care control arm; however, previous studies have shown superior hypoglycemia results using HCL with exercise as compared with standard care. ${ }^{7,23}$ In addition, exercise sessions were not standardized on subsequent days for intensity, duration, or pre-exercise supplemental CHO consumption, so it is not possible to directly compare the two announcement strategies. Only one type of exercise was studied and, therefore, the results may not apply to other types of exercise, such as high-intensity interval training or 
extended periods of intense aerobic exercise. ${ }^{1}$ Lastly, the study had a relatively short duration of HCL conducted in a supervised hotel setting. Additional challenges to the algorithm may be faced in an unsupervised environment or when the system is used for longer periods of time.

\section{Conclusions}

This feasibility study demonstrated that the Omnipod personalized MPC algorithm performed well and was safe for $54 \mathrm{~h}$ of use by adults in the outpatient hotel setting. In addition, the system was able to maintain good glycemic control within target ranges in the presence of glucose set point changes and moderate intensity exercise. The exercise announcement strategies of either a temporarily raised glucose set point or reduced basal rate $90 \mathrm{~min}$ before exercise were found to be safe methods to prepare for exercise during HCL, with some subjects consuming supplemental $\mathrm{CHO}$ before or after exercise. No subject experienced hypoglycemia on either night after exercise. Longer term outpatient studies will assess safety and performance of the algorithm during extended use under free-living conditions in patients of all ages with T1D.

\section{Acknowledgments}

The authors thank the study participants and their families and the dedicated staff at the participating research centers, including Laya Ekhlaspour, MD, Liana Hsu, Lisa Norlander, MD, Ryan Kingman, and Sarah Loebner of Stanford University Medical Center, Stanford, CA; Cari Berget, RN, CDE, MPH, Katelin Thivener, BS, Robert Slover, MD, G. Todd Alonso, MD, and Brigitte Frohnert, MD, PhD, of the Barbara Davis Center for Diabetes, University of Colorado Denver, Denver, CO; and the staff at Diablo Clinical Research Center, Walnut Creek, CA. We appreciate the efforts of the research and development and clinical teams at Insulet Corp., including Bonnie Dumais, Connor Gullifer, Stephanie Mandra, Todd Vienneau, and Yibin Zheng, PhD. This work was funded by Insulet Corporation.

\section{Author Disclosure Statement}

Dr. Forlenza has received research funding from Abbott, Bigfoot Biomedical, Dexcom, Insulet Corp., Medtronic, Novo Nordisk, Tandem, and Type Zero, and is a speaker and advisory board member for Dexcom and Tandem.

Dr. Buckingham served as the principal investigator for the study and received research funding from Insulet Corp., and has received research support from Bigfoot Biomedical, Dexcom, Medtronic, and Tandem, and is an advisory board member for Becton Dickinson, NovoNordisk, and Sanofi.

Dr. Wadwa has received research funding from Bigfoot Biomedical, Dexcom, Insulet Corp., Lexicon Pharmaceutical, Medtronic, Novo Nordisk, Tandem, and Xeris Pharmaceutical, and is an advisory board member for Eli Lilly \& Co and a speaker for Dexcom.

Dr. Christiansen has received research funding from Abbott Diabetes Care, Dexcom, Insulet Corp., and Medtronic.

Dr. Peyser is a consultant to Insulet Corp. and has consulted for Dexcom.

Dr. Dassau is a consultant to Insulet Corp. and has received research support from Dexcom, Tandem, Roche, Insulet, and Xeris.
Drs. Ly, Lee, Huyett, and Layne and Mr. O'Connor are employees of Insulet Corp.

\section{Supplementary Material}

Supplementary Data

Supplementary Figure S1

Supplementary Table S1

\section{References}

1. Riddell MC, Gallen IW, Smart CE, et al.: Exercise management in type 1 diabetes: a consensus statement. Lancet Diabetes Endocrinol 2017;5:377-390.

2. Brazeau AS, Rabasa-Lhoret R, Strychar I, et al.: Barriers to physical activity among patients with type 1 diabetes. Diabetes Care 2008;31:2108-2109.

3. Jabbour G, Henderson M, Mathieu ME: Barriers to active lifestyles in children with type 1 diabetes. Can J Diabetes 2016;40:170-172.

4. Lascar N, Kennedy A, Hancock B, et al.: Attitudes and barriers to exercise in adults with type 1 diabetes (T1DM) and how best to address them: a qualitative study. PLoS One 2014;9:e108019.

5. Huyett LM, Ly TT, Forlenza GP, et al.: Outpatient closedloop control with unannounced moderate exercise in adolescents using zone model predictive control. Diabetes Technol Ther 2017;19:331-339.

6. Dove K, Macedoni M, Bratina N, et al.: Closed-loop glucose control in young people with type 1 diabetes during and after unannounced physical activity: a randomised controlled crossover trial. Diabetologia 2017;60:21572167.

7. Breton MD, Chernavvsky DR, Forlenza GP, et al.: Closed loop control during intense prolonged outdoor exercise in adolescents with type 1 diabetes: the Artificial Pancreas Ski study. Diabetes Care 2017;40:1644-1650.

8. Zisser H, Dassau E, Lee JJ, et al.: Clinical results of an automated artificial pancreas using technosphere inhaled insulin to mimic first-phase insulin secretion. J Diabetes Sci Technol 2015;9:564-572.

9. Cameron FM, Ly TT, Buckingham BA, et al.: Closed-loop control without meal announcement in type 1 diabetes. Diabetes Technol Ther 2017;19:527-532.

10. Mauseth R, Lord SM, Hirsch IB, et al.: Stress testing of an artificial pancreas system with pizza and exercise leads to improvements in the system's fuzzy logic controller. J Diabetes Sci Technol 2015;9:1253-1259.

11. Haidar A, Rabasa-Lhoret R, Legault L, et al.: Single- and dual-hormone artificial pancreas for overnight glucose control in type 1 diabetes. J Clin Endocrinol Metab 2016; 101:214-223.

12. Dassau E, Brown SA, Basu A, et al.: Adjustment of openloop settings to improve closed-loop results in type 1 diabetes: a multicenter randomized trial. J Clin Endocrinol Metab 2015;100:3878-3886.

13. Pinsker JE, Laguna Sanz AJ, Lee JB, et al.: Evaluation of an artificial pancreas with enhanced model predictive control and a glucose prediction trust index with unannounced exercise. Diabetes Technol Ther 2018;20:455464.

14. Ly TT, Buckingham BA, DeSalvo DJ, et al.: Day-and-night closed-loop control using the unified safety system in adolescents with type 1 diabetes at camp. Diabetes Care 2016; 39:e106-e107. 
15. Jayawardene DC, McAuley SA, Horsburgh JC, et al.: Closed-loop insulin delivery for adults with type 1 diabetes undertaking high-intensity interval exercise versus moderateintensity exercise: a randomized, crossover study. Diabetes Technol Ther 2017;19:340-348.

16. Taleb N, Emami A, Suppere C, et al.: Efficacy of singlehormone and dual-hormone artificial pancreas during continuous and interval exercise in adult patients with type 1 diabetes: randomised controlled crossover trial. Diabetologia 2016;59:2561-2571.

17. Forlenza GP, Cameron FM, Ly TT, et al.: Fully closed-loop multiple model probabilistic predictive controller artificial pancreas performance in adolescents and adults in a supervised hotel setting. Diabetes Technol Ther 2018;20: 335-343.

18. Jacobs PG, El Youssef J, Reddy R, et al.: Randomized trial of a dual-hormone artificial pancreas with dosing adjustment during exercise compared with no adjustment and sensor-augmented pump therapy. Diabetes Obes Metab 2016;18:1110-1119.

19. Patel NS, Van Name MA, Cengiz E, et al.: Mitigating reductions in glucose during exercise on closed-loop insulin delivery: the Ex-Snacks study. Diabetes Technol Ther 2016;18:794-799.

20. DeBoer MD, Chernavvsky DR, Topchyan K, et al.: Heart rate informed artificial pancreas system enhances glycemic control during exercise in adolescents with T1D. Pediatr Diabetes 2017;18:540-546.

21. Breton MD, Brown SA, Karvetski CH, et al.: Adding heart rate signal to a control-to-range artificial pancreas system improves the protection against hypoglycemia during exercise in type 1 diabetes. Diabetes Technol Ther 2014;16: 506-511.

22. Turksoy K, Hajizadeh I, Hobbs N, et al.: Multivariable artificial pancreas for various exercise types and intensities. Diabetes Technol Ther 2018;20:662-671.

23. Castle JR, El Youssef J, Wilson LM, et al.: Randomized outpatient trial of single- and dual-hormone closed-loop systems that adapt to exercise using wearable sensors. Diabetes Care 2018;41:1471-1477.

24. Buckingham BA, Christiansen MP, Forlenza GP, et al.: Performance of the omnipod personalized model predictive control algorithm with meal bolus challenges in adults with type 1 diabetes. Diabetes Technol Ther 2018;20:585-595.

25. Buckingham BA, Forlenza GP, Pinsker JE, et al.: Safety and feasibility of the OmniPod hybrid closed-loop system in adult, adolescent, and pediatric patients with type $1 \mathrm{di}-$ abetes using a personalized model predictive control algorithm. Diabetes Technol Ther 2018;20:257-262.

26. Clarke WL, Cox DJ, Gonder-Frederick LA, et al.: Reduced awareness of hypoglycemia in adults with IDDM. A prospective study of hypoglycemic frequency and associated symptoms. Diabetes Care 1995;18:517-522.

27. American Diabetes Association. Glycemic targets. Sec. 6. In Standards of Medical Care in Diabetes - 2017. Diabetes Care 2017;40(Suppl. 1):S48-S56.

28. Dassau E, Zisser H, Palerm CC, et al.: Modular artificial beta-cell system: a prototype for clinical research. J Diabetes Sci Technol 2008;2:863-872.

29. Maahs DM, Buckingham BA, Castle JR, et al.: Outcome measures for artificial pancreas clinical trials: a consensus report. Diabetes Care 2016;39:1175-1179.
30. Campbell MD, Walker M, Bracken RM, et al.: Insulin therapy and dietary adjustments to normalize glycemia and prevent nocturnal hypoglycemia after evening exercise in type 1 diabetes: a randomized controlled trial. BMJ Open Diabetes Res Care 2015;3:e000085.

31. Davey RJ, Howe W, Paramalingam N, et al.: The effect of midday moderate-intensity exercise on postexercise hypoglycemia risk in individuals with type 1 diabetes. J Clin Endocrinol Metab 2013;98:2908-2914.

32. Gomez AM, Gomez C, Aschner P, et al.: Effects of performing morning versus afternoon exercise on glycemic control and hypoglycemia frequency in type 1 diabetes patients on sensor-augmented insulin pump therapy. J Diabetes Sci Technol 2015;9:619-624.

33. Tsalikian E, Mauras N, Beck RW, et al.: Impact of exercise on overnight glycemic control in children with type 1 diabetes mellitus. J Pediatr 2005;147:528-534.

34. Reddy R, El Youssef J, Winters-Stone K, et al.: The effect of exercise on sleep in adults with type 1 diabetes. Diabetes Obes Metab 2018;20:443-447.

35. Zaharieva D, Yavelberg L, Jamnik V, et al.: The effects of basal insulin suspension at the start of exercise on blood glucose levels during continuous versus circuit-based exercise in individuals with type 1 diabetes on continuous subcutaneous insulin infusion. Diabetes Technol Ther 2017;19:370-378.

36. Roy-Fleming A, Taleb N, Messier V, et al.: Timing of insulin basal rate reduction to reduce hypoglycemia during late postprandial exercise in adults with type 1 diabetes using insulin pump therapy: a randomized crossover trial. Diabetes Metab 2018. [Epub ahead of print]; doi: 10.1016/ j.diabet.2018.08.002.

37. Zaharieva D, McGaugh SM, Pooni R, et al.: Reducing basal insulin 90 minutes before exercise protects against hypoglycemia better than insulin suspension at exercise onset in T1D—the OmniTIME results. Diabetes 2018;67(Suppl 1): A17.

38. Weisman A, Bai JW, Cardinez M, et al.: Effect of artificial pancreas systems on glycaemic control in patients with type 1 diabetes: a systematic review and meta-analysis of outpatient randomised controlled trials. Lancet Diabetes Endocrinol 2017;5:501-512.

39. Monnier L, Colette C, Wojtusciszyn A, et al.: Toward defining the threshold between low and high glucose variability in diabetes. Diabetes Care 2017;40:832-838.

40. Beck RW, Connor CG, Mullen DM, et al.: The fallacy of average: how using $\mathrm{HbA1c}$ alone to assess glycemic control can be misleading. Diabetes Care 2017;40:994-999.

41. Shahraz S, Pittas AG, Saadati M, et al.: Change in testing, awareness of hemoglobin a1c result, and glycemic control in us adults, 2007-2014. JAMA 2017;318:1825-1827.

Address correspondence to:

Gregory P. Forlenza, MD

Barbara Davis Center for Diabetes

University of Colorado School of Medicine

1775 Aurora CT

MS A140

Aurora, CO 80045

E-mail: gregory.forlenza@ucdenver.edu 